\title{
Analysis of coastal protection forest research content based on bibliometrics in China
}

\author{
Yu-Dan Sun ${ }^{+}$\& Jin-Xiang Liu ${ }^{+} \&$ Ping-Hui Huo \\ Life Science and Technology School, Lingnan Normal University, Zhanjiang, 524048, China \\ Burningice80@163.com, lightlong@163.com, lovelymabelhuo@126.com \\ +The author contributed equally to this work \\ *For correspondence: Burningice80@163.com
}

Keywords: coastal protection forest; CNKI; bibliometrics; research progress; China

\begin{abstract}
Coastal protection forest were selected from China National Knowledge Infrastructure (CNKI), including scientific research papers, dissertations, conference papers et al, to conduct bibliometric statistics of literature number, level and highly cited frequency literatures distribution. The results indicated that Casuarina, sandy coast, selection of tree species, ecological benefit and shelterbelt construction were the hot topics; soil microorganism, remote sensing, site conditions and muddy coast were emerging topics. We also revealed the stages and trends of coastal protection forest research, which varied from different periods. The future research may focus on monitoring and evaluation, structure optimization and integrated management to coastal protection forest ecosystem.
\end{abstract}

\section{Introduction}

Coastal protection forest has the function which wind prevention and sand fixation, preserve soil and water, protect the village cities and farms, regulate climate, improve the ecological environment, protect biodiversity, etc(Ye Gong-fu et al.,Fang Fa-zhi et al.,Yu De-shui et al.). Of the coastal shelter forest research helps to maximize its ecological protective effect. China has $18340 \mathrm{~km}$ of coastline involving 11 provinces and cities, which densely populated and economically developed, is the most important part of economic and social development, but often from being destroyed by the typhoon and storm surge(Cheng Xiang-rong et al.). "Matsa" typhoon to coastal areas caused direct economic losses as high as 17.71 billion CNY and more than 30 million people affected in 2005(Zhang Qing-hong et al.). Therefore, develop wind disaster reduction research is very important(Emanuel K A.). Building coastal shelter forest system is the most effective measures against wind in the maintenance of land ecological security and safeguard social and economic development plays an important role(Zhang Ji-lin et al.).

Survey and phase change in the studies of the coastal shelter forest, hot spot and focus areas for identification. Reveal the change and development trend in order to provide reference for the study of the coastal shelter forest science.

\section{Data sources and research methods}

The data root in China National Knowledge Infrastructure (CNKI) and retrieval time range from 1950 to 2014 years. According to the retrieval ways, literature can be divided into two types of research and practical literature. Research literature including journal articles, master's graduation thesis, and conference papers, practical literature including achievements, patents and standards.

\section{Hotspot phase evolution analysis}

\section{The initial stage}

In 1953-1980 belongs to the coastal protection forest construction and research of infancy in China. This phase of the research focuses on how to start building the coastal shelter forest and 
casuarina as the research hot spot, its height and protective effect is concerned. Start planting is given priority to with casuarina in Fujian province took the lead in coastal areas of coastal shelter forest to withstand frequent typhoons.

\section{Slow developmental stage}

In $1981 \sim 1990$ belongs to the slow development of the coastal shelter forest research stage, and the stage had the obvious development research topics. The object of study has a bigger breakthrough, the content of the study more specific. Began to have a special fund to support, pay more attention to comprehensive benefit and long-term planning.

\section{Rapid development stage}

In $1991 \sim 2005$ belongs to the rapid development of the coastal shelter forest research phase and research scope is expanding fast. At this stage the appearance of some new research topics, such as sustainable development of forestry ecological engineering, and plain afforestation, etc. Wide range of subjects, the ecological public welfare forest, mangroves, pine, pinus elliottii and forest resource has been the subject of study. Site conditions give priority to with sandy coast and rocky coast. Begin to pay close attention to the overall environment effect and focus on the practical countermeasures are proposed according to the status quo.

\section{Overall development stage}

In 2006 2014 belongs to the all-round development of the coastal shelter forest research stage, and research scope to the stable. Research focus has changed, remote sensing is an important trend in current study of the coastal shelter forest, namely using "3s" technology for dynamic monitoring.

\section{Expectation}

Future research will focus on monitoring and evaluation in the coastal shelter forest, system and structure optimization, and comprehensive management of coastal shelter forest ecological system.

\section{The core keyword analysis}

Coastal shelter forest, casuarina, sandy coast, the coastal areas, tree species selection, ecological benefits and protection forest construction as the core keywords with the highest frequency. Mangroves, countermeasures, comprehensive evaluation and upgrading for the major study of the coastal shelter forest. Soil microorganisms, remote sensing, site conditions, muddy coast is the direction of the researchers are trying to break through.

\section{Hot direction analysis}

The current hot spot in the coastal shelter forest can be divided into three directions. The first is shelter forest tree species selection and pest control research, the second is the protective structure function and optimization technology research, the third is the different site conditions for afforestation technology and benefit research. Hou Qian et al. studied on the tree species selection of typhoon shelter forest in Hainan tropical coastal. Try to select tree species which the wind resistance and landscape features were superior(Hou Qian et al.). Kong Zheng-hong et al. using the GIS spatial analysis and landscape pattern analysis method and sampling survey of shelter belt community structure reviewed forest structure and function of the spatial heterogeneity from different levels of Chongming island coastal shelter (Lin Wen-huan et al.). Liao Xiao-li et al. measured and analyzed the suitable site conditions of casuarina on soil type, soil thickness, altitude and slope make use of " 3 s ”technology and divided the site conditions (Kong Zheng-hong et al.).

\section{Conclusion}

(1) Afforestation technology in difficult site and the selection of salt-tolerant waterlogging-enduring tree species(LiaoXiao-li et al.). Especially in the coastal areas in China and changeable natural geographical conditions, adjust measures to local conditions of forest management plan formulation is the key to further play to the coastal shelter forest protection function.

(2) Using "3s" and PC technology research, monitoring and management of the coastal shelter forest(Li Xiao-rong et al.). Research on environmental factors, especially the soil, the interaction of 
wind and shelter forest helps to create a high quality of the coastal shelter forest (Liang Yi et al.).

(3) Shelter forest fire prevention, pest, man-made destruction and other work of the management (Hong Yuan-cheng et al., Huang Shui-jin et al., Zeng Li-qiong et al.). Perfect policies, laws and regulations, bring the coastal protection forest management into the state's public utility management system, persistently develop the function of the coastal shelter forest.

\section{Acknowledgements}

This research is supported by National Spark Program of China (Grants: 2013GA780075) and Zhanjiang key laboratory project of tropical plant resources and development (No. 2014A06008).

\section{References}

[1] Ye Gong-fu et al.Ecosystem Processes and Sustainable Management of Coastal Protection Forest of casuarina equisetifolia. World forestry research. 2012, (3):32-37.

[2] Fang Fa-zhi et al.Construction Benefit Evaluation of Coastal Shelter Forest System in Hainan Province. Journal of Central South University of Forestry \& Technology. 2013, (11):115-119.

[3] Yu De-shui et al.The Position and Functions of Forestry Construction in the Northeast of the Coastal Shelter Forest System. Forest Resources Management. 2000, (6):36-38.

[4] Cheng Xiang-rong et al.Review on Construction Technology of Coastal Shelterbelt Project. World Forestry Research.2009, (1):63-67.

[5] Zhang Qing-hong et al.The typhoon influence research in China mainland. Chinese Science. 2010, (7):941-946.

[6] Emanuel K A. Increasing destructiveness of tropical cyclones over the past 30 years. Nature, 2005, 436: 686 -689

[7] Zhang Ji-lin et al.The Strucure, Function and Developing Tendency of

The Coastal Windbreak System. World Forestry Research. 1998, (1):51-57.

[8] Hou Qian et al.Selection of Tree Species for anti-Typhoon Shelter Forests of Tropical Coastal City in Hainan. Journal of Central South University of Forestry \& Technology.2011, (5):184-191.

[9] Lin Wen-huan et al.Early Growth of 5 Tree Species in Rocky Roast Sites Difficult to Be Afforested in the Eastern of Guangdong Province. Journal of Central South University of Forestry \& Technology.2012, (8):18-21.

[10] Kong Zheng-hong et al.Spatial Heterogeneity of Structure and Function of the Coastal Shelterbelts in Chongming Island. Scientia Silvae Sinicae.2009, (4):60-64.

[11] LiaoXiao-li et al.Study on Suitable Site Condition of Main Afforestation Tree Species casuarina equisetifolia in Coastal Shelterbelt Forest. Journal of Fujian College of Forestry. 2012, (2):107-112.

[12] Li Xiao-rong et al.Analysis of Soil Physicochemical Properties and Biological Activity of the casuarina equisetifolia Forests with Different Ages. Journal of Northwest Forestry University, 2014, (2):37-41.

[13] Liang Yi et al.A Review of Application of Remote Sensing Technology to Coastal Shelterbelt Forest. World Forestry Research. 2010, (2):33-38.

[14] Hong Yuan-cheng et al.Investigation on the Dynamics of the Landscape Pattern of Coastal

Protection Forest in Jinjiang during the Past 20 Years. Forest Resources Management. 2010, (3):69-74.

[15] Huang Shui-jin et al.Advanced in Occurrence Present and Control Methods of Major Pest in 
Coastal Protection Forest on the Coast of Southeast China. Journal Of Fujian Forestry Science And Technology. 2012, (1):165-170.

[16] Zeng Li-qiong et al.Resistance Identification of 48 casuarina Clones to anoplophora chinensis. Journal of Nanjing Forestry University. 2014, (5):51-56. 